\title{
Emotional aspects of chronic disease
}

\author{
DAVID A. BARON, D.o
}

Pasadena, California

As physicians, we are trained to treat disease and promote health, unfortunately in that order. As osteopathic physicians, we are schooled in treating the whole person, not just the dysfunctional organ. There is a psychologic as well as a physiologic reaction to every disease process, and having a general understanding of the emotional reactions to chronic disease can greatly enhance the delivery of clinical care.

\section{The bio-psychosocial model}

As Simons and Pardes" have observed, "What is spoken of as a clinical picture is not a photograph of a man sick in bed; it is an impressionistic painting surrounded by his home, his work, his relations, his friends, his joys, sorrows, hopes and fears." Chronic physical illness is associated with a variety of emotional problems. The specific nature of the illness (biologic/biomedical factors), the personality and coping style (psychologic factors), and the current life circumstances (social factors) of the patient all must be considered in understanding his/her problems and in formulating a comprehensive treatment plan.

Engel $^{2}$ and others ${ }^{3,4}$ have noted that the dominant model of disease taught in preclinical medical education is biomedical, with molecular biology its basic scientific discipline. This model assumes that disease can be fully accounted for by deviations from the norm of measurable biologic variables, thus leaving no room within its structure for the social, behavioral, and psychologic dimensions of illness. As a result, medical students rarely attain insight into the clinical value of patient conceptualization from a biopsychosocial perspective and its critical importance in the care of the chronically ill. Those students who are taught these concepts tend to view biologic, psychologic, and social aspects of the patient as separate entities, rather than realizing the intricate interplay of these parts.

The experienced clinician learns to appreciate these issues in attending to the whole person. Good bedside manner incorporates an overall understanding of biopsychosocial issues as they pertain to patient management.

\section{Emotional reactions to disease}

When a person becomes ill, he/she is confronted not only with physical discomfort but with the unique psychologic significance of being sick. Coping behaviors that have been successful in day-to-day life are challenged, thus requiring the development of new, or the resurrection of old coping styles. Stress, generated from feelings of loss, is of paramount importance. The patient who is suffering from a chronic illness is confronted with a multitude of losses. The easiest to identify for both the patient and the physician are the real losses; most commonly these are loss of bodily function, income, mobility, and various activities. However, symbolic loss and fantasized loss, despite being much more difficult to identify, usually evoke a more severe emotional response. Symbolic and fantasy losses are often centered around the same event. For example, a woman undergoes a mastectomy and experiences a loss of her feminity/her breast symbolizing her womaness. Also, as the result of this symbolic loss, she fantasizes the loss of her husband's love and affection, regardless of the level of his actual response. It should be kept in mind that fantasied losses can become real losses.

Regression is one of the most common emotional responses to illness. Passivity and dependency, associated with the onset of illness and its treatment, 
can lead to a regression to a psychologic state appropriate to a time in the patient's life where dependency was accepted — childhood. ${ }^{5}$ Despite the difficulty that this demanding, childlike behavior with low frustration tolerance can create for caregivers and family, it can serve an important function for the patient. The relief of anxiety associated with feelings of dependency and loss of control allows the patient to be more compliant in accepting care. It also makes it easier for the patient to return to the responsibilities of adulthood when his/her condition allows, without feeling embarassed about their behavior. Regression can become detrimental if (1) it becomes too severe/or (2) it goes on too long. Although the overly dependent, passive, compliant patient might cause little problems for the clinician initially, prolonged behavior of this type stands in the way of effective long-term care.

Previous experiences with illness and caretaking affect a patient's reactions to illness in the present (illness behavior). Patients who have learned that caregivers can be relied upon to protect them, and that becoming ill is not a devastating experience, can accept the need to depend on others, relinquish control gracefully, and better tolerate loss of function and separation from loved ones. On the other hand, patients who have received inconsistent or unreliable caretaking, and who have met with uncaring or angry responses when they were sick, are likely to be untrusting and apprehensive of their physicians, their present-day unconscious parental figures. ${ }^{6,7}$ This situation can be very frustrating for the empathic doctor who cannot understand why the patient acts out in an angry or ungrateful way despite his or her best clinical efforts. It must be remembered that the patient is responding unconsciously as if the doctor were the parent, or someone else of importance (transference phenomena). Although the initial response from the physician might be anger or confusion over the patient's behavior, if the actions have no basis in reality, the clinician should consider the possibility of unconsciously motivated acting out. Making a patient consciously aware of what they are doing in a nonaccusatory fashion can prove helpful.

Another commonly seen emotional reaction of the chronically ill patient is denial. This is often present in conditions where pain is minimal or absent, such as in hypertension. In an attempt to deal with the anxiety generated by being ill and/or hospitalized, the patient may seem to ignore the severity of his/her condition. As with regression, this can be very frustrating for the family and attending physician, who often view this as conscious noncompliant behavior. Like other ego defense mechanisms, keeping anxiety within tolerable limits serves a valuable function. Excess anxiety and stress contribute to underlying depression and the increased secretion of catecholamines, which adversely affect the recovery process. It is important for the clinician to be aware of and address the issue of denial. Even though it does help to bind anxiety, it can lead to dangerous noncompliant behavior. Common examples include the cardiac or hypertensive patient who ignores diet, exercise, and medication recommendations, or the chronic obstructive pulmonary disease patient who continues to smoke. Again, making the patient aware of his/her behavior while offering alternative stress reducing and coping skills in an empathic manner is paramount if one is to achieve optimal therapeutic results.

\section{Patient management}

To successfully intervene, the clinician must first identify what the patient is afraid of and how the particular illness is evoking anxiety. The best way to obtain this information is to discuss the matter with the patient. As an experienced clinician, it is tempting to assume that one knows the patient's inner fears. However, what is assumed to be the patient's anxieties is often one's own if confronted with a similar situation-not the patient's. Important issues to explore include altered body image, deterioration of self esteem, fear of loss of love and acceptance, fear of death, loss of sexual functioning, fear of relying on strangers for care, feelings of guilt (illness is punishment for past acts), fear of loss of control, fear of pain, and separation from family. Once identified, the physician can intervene appropriately.

Educating a patient about his/her illness and its treatment is very effective in reducing anxiety and increasing compliance in most patients. When a patient understands why taking medication at specific times, despite lack of ongoing symptoms, is important, he/she is more likely to comply. Also, a well-educated patient recognizes early warning signs and knows the importance of prompt intervention. It is amazing to discover how many fears are based on fantasy rather than fact. Allowing a patient to take an active role in his/her treatment is beneficial for both the patient and the doctor. The patient tends to feel less out of control if he/she is included in treatment decisions, leaving the doctor with a more compliant patient. The importance of empathy (understanding how it must be for the patient) and genuine concern on the part of the physician cannot be overstated. When potential pain is an issue, assure the patient that every effort will be made to manage it. Always attempt to give the patient something to feel hopeful about. Even 
the post-therapeutic patient can look forward to better pain management and improved sleep, for example. Allow patients to express their fears and help them deal with them. This can be remarkably effective in reducing anxiety and stress. Spiritual issues should be addressed and appropriate personnel made available to the patient when appropriate.

When should the primary care physician refer a patient for psychiatric consultation, and how should it be done? Patients who manifest acute maladaptive changes in behavior, who report or show feelings of helplessness or hopelessness, who have a past psychiatric history, or any patient the physician feels uncomfortable about, should be referred for psychiatric consultation. The patient should be informed that the stress of having a chronic illness is difficult for anyone and that a respected colleague can work with him/her to help increase the effectiveness of the total treatment plan. Never have a patient feel that they are being "shipped to the shrink." Not only will the patient feel abandoned, but the psychiatrist will be greatly hampered.

$\overline{1 . \text { Simons, R.C., and Pardes, H.: Comparison of educational and medical }}$ models. Understanding human behavior in health and illness. Ed. 2. Williams \& Wilkins Co., Baltimore, 1981

2. Engel, G.L.: The need for a new medical model. A challenge for biomedicine. Science 196:129-36, 8 Apr 77
3. Edelstein, P., Ross, W.D., and Schultz, J.R.: The biopsychosocial approach. Clinical examples from a consultation-liaison service. Psychosomatics 23:15-9, Jan 82

4. Silverman, D., et al.: In search of the biopsychosocial perspective. An experiment with beginning medical students. Am J Psychiatry 140:1154-9, Sep 83

5. Boucharlat, J., et al.: Hospitalization and regression. Ann Med Psychol $582: 5$, Nov 74

6. Krupp, N.E.: Adaptation to chronic illness. Postgrad Med 60:122-5, Nov 76

7. Mechanic, D.: Illness behavior, social adaptation, and the management of illness. J Nerv Ment Dis 165:79-87, Aug 77

Dubovsky, S.L., and Weissberg, M.P.: Clinical psychiatry in primary care Ed. 2. Williams \& Wilkins Co., Baltimore, 1983

Moos, R.H.: In Psychiatry for the primary care physician, edited by A.L. Freeman, et al. Williams \& Wilkins Co., Baltimore, 1983

Strain, J.J.: Psychological interventions in medical practice. AppletonCentury-Crofts, New York, 1978

Accepted for publication in July 1986. Updating, as necessary, has been done by the author.

Dr. Baron is an assistant professor of psychiatry, and chief of psycho-oncology at Norris Cancer and Research Institute, University of Southern California, School of Medicine, Los Angeles, California.

Dr. Baron, University of Southern California, School of Medicine, Hoffman Research Building Room 101, 2025 Zonal Avenue, Los Angeles, California 90033. 


\begin{tabular}{ll|l} 
OSTEOPATHIC RESEARCH: \\
GROWTH AND DEVELOPMENT
\end{tabular}

- General History-Wilbur V. Cole, DO

- Anatomical and Histopathological Evidence

-Wilbur V. Cole, DO

- Biomechanics-Myron C. Beal, DO

- Physiology —Albert F. Kelso, PhD

- Clinical Research-Myron C. Beal, DO

- Status and Future of Osteopathic Research

-Albert F. Kelso, PhD

Alexandra A. Townsend, DO

An excellent source for students, teachers, researchers, and practitioners.

Send check and order form to:

American Osteopathic Association

212 E Ohio Street

Chicago, Illinois 60611

Attn: Order Department

Please send me: hardcover copies of Osteopathic Research: Growth and Development (\$11 each) $\$$ 

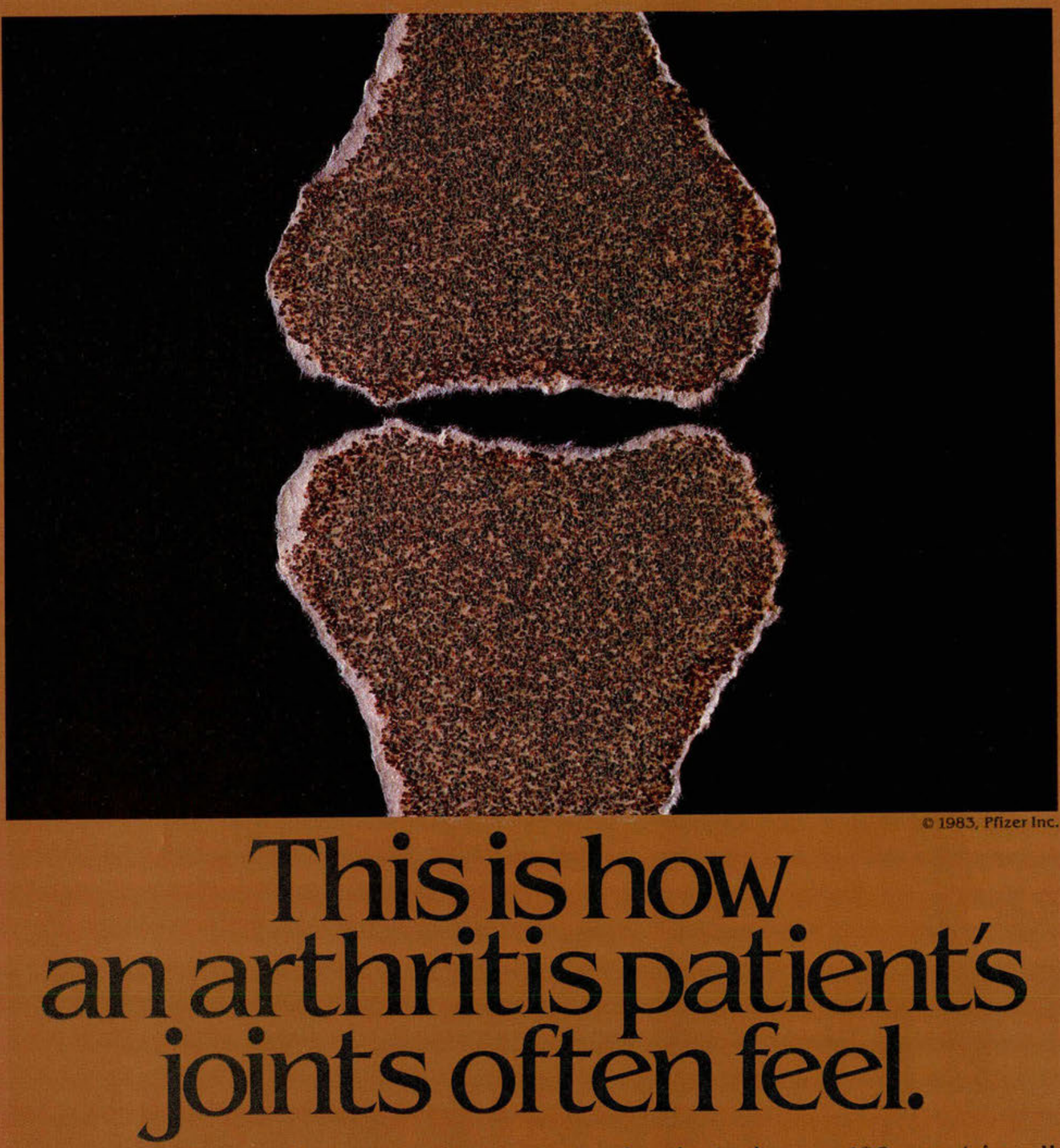

You can help these patients feel better with one-a-day FELDENE* (piroxicam). For good reasons:

- it's effective - proven relief of the pain and inflammation of rheumatoid arthritis and osteoarthritis' in millions

of patients, in over 100 countries all around the world.

- it's efficient-once daily, 20-mg dose provides round-the-clock relief, improves compliance and remains effective during long-term therapy.

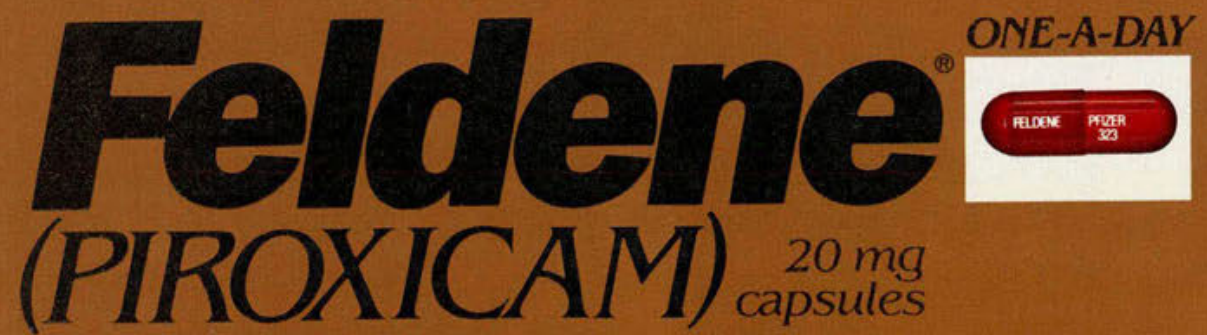

Please see FELDENE (piroxicam) brief summary on the following page. 
Indicates maximum dosage for osteoarthritis and rheumatoid arthritis for the antiarthritic agents $\quad$ Source: PDR, 1987, Manufacturers' Prescribing Information.

Briet Summury

FELEGE $*$ Giroricam) Copsules

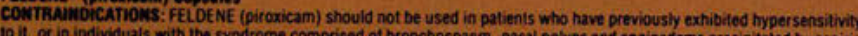
10it. or in individuals with the syndrome comprised of bronchospasm, nasal polyps and anpioedema preciptated by aspirin

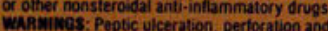

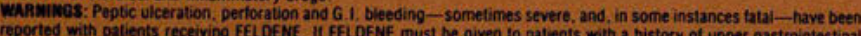
Teportiod with patients receiving FELDENE. II FELOENE must be given to patients with a history of upper gastrointestinal

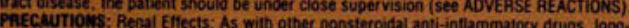

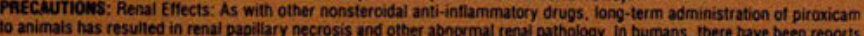

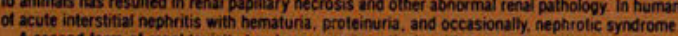

A second lorm of ronal toxicily has been seen in patients with pretenal conotitions leading to a reduction in renal bloge now or biood volume, where the renal prostaglandins have a supportive role in the maimtenance of renal perfusion. In inese patients administration of an NSAIO may cause a dose-dependent reduction in prostaglandin formation and may precioilate overt tenal decompensation. Patents at preatest risk of this reaction are those with impaired renal function, heart bilure.

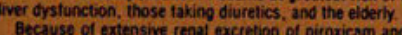

excecause of extensive reasa excretion of piroxicam and its biotranstormation products (less than $5 \%$ of the daily dose Dhould be anticipaled in patients with impasired renal function, and they Although other nonsterolid

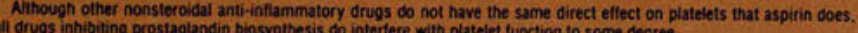
Because of reports of adverse

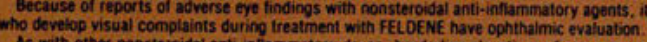

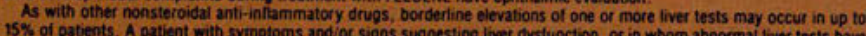
occurred, should be evaluated for feridence of the deveriopment of more severe heastic reaction while on theragy with

Severe hepatic reactions, including jaundice and cases of tatal hepatitis have been reported with FELOENE. Athough such reactions are rare, if abnormal iver lests persist or worsen, it clinical signs and symptoms consistent with liver disease develop, or it systemic manilestations occur ie.0. eosinoophilis, rash. eic.). FELDENE should be discontinved. (Set Athough at the recommended dose of 20 mo day of FEL DENE increased fecal blood loss due 10 gastrointestinal irritation Gid not oceut, in about 4\% of the patients treated with FELDENE alone or concomilantly with aspirin reductions in $\mathrm{m}$. moglooin and hematocrit values were obsetvec

Peripheral edema has been ooserved in approximately $2 \%$ of the patients treated with FELOENE. Thereflore. FELDENE shoule be used with caution in patients with heart lailure, hypertension of other conoditions predisposing to fluid retention A combination of dermatological andior allergic signs and symptoms suggestive of serum sickness have occasionality

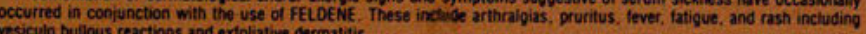
resiculo bullous reactions and extoliative dermatitis

Theretore macriows: Interactions with coumarin-iype anticoagulants have been reported with FELDENE since marketing Thereiore, physicians shoula closely monitor patients for a chánge in dosage requirements when administering fELOENE 10 patients on coumarin-type anticoagulants and other highty profein- bound drugs

Hessma levelis of piroxicam are oepressed to approximately $80 \%$ of their normal values when FELDENE is administered levels.

Nonsteroical anti-inflammatory agents, including FELDENE. have been reported to increase steady state plasma tithivm

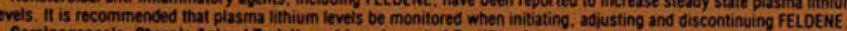
Carcelaopenesis. Chronic Animal Toxicity and impairment of Fertility: Subacute and chronic toxicity studies have been carried out in rats. mice, dogs, and monkeys.

The patthology most often seen was that characteristically associateo with the animal toxicolooy of anti-inflammatory In classicas papillary necrosis (see PRECAUTIONS) and gastrointestinat lesions

In classical studies in laboratory animals, piroxicam oid not show ary teratogenic potential.

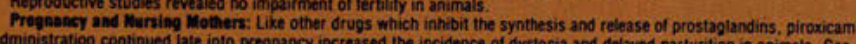
trointestinal tract loxicity was increased in pregnant lemales in the ist trimester of delayed parturition in animals. Ga: lemales of temales in earlier trimesters of pregnancy

FEL DENE is not recommended for use in nursing mothers or in pregnant momen Deccuse of the animal findings and since satey for sucti use has not been estibitshed in fumans.

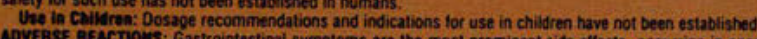

AOVERSE RESCTnOMs: Gastrointestinal symptoms are the most prominent side efflects, occurring in approximatety 20\%

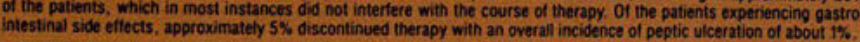

Adverse reactions are listed below by body system tor all patients in clinical trials with fELDENE (oiroxicam) at doses of $20 \mathrm{mg}$ day.

incidence Greater Than $1 \%$ : The foliowing adverse reactions occurred more frequently than 1 in 100 .

Gastrountestinaf: stomatitis, anorexia, epigastric distress; nausea; constipation, abdominal discomfort, flatulence, di. amea, abdominal pain, indigestion

hematological: decreases in hemoglobin" and hematocrit" (see PRECAUTIONS). anemia, leucopenia, eosinophilia Dermalologic pruritus, rast

Central Nervous System: diziness, somnolence, vertigo

Urogenita: BUN and creatinine eievations isee PRECAUUTIONS)

Body as a whole: headacine.
Special Senses: tinnitus

Cardiovascular:Respiratory codema (see PRECAUTIONS)

- Reactions occurring in $3 \%$ to $9 \%$ of patients treated with FELDENE

Reactions occurting in $1 \%$ to $3 \%$ of patients are unmarked

Incidence Leas Than 1\% (Causal Relationship Probable): The following adverse reactions occurred less frequently than in 100. The probability exists that there is a causal retationship between fEL DENE and these reactions.

Gastrointestinal: liver function abnormalities, jaundice, hepatitis (see PRECAUTIONS). vomiting, hematemesis, melena: gastrointestinal bleeding, perforation and ulceration (see WARNINGS), dry mouti

Hematological: thrombocytopenia, petechial rash, ecchymosis, bone marrow depression including aplastic anemia,

Dermatalogic: sweating, erythema, bruising, desquamation, exiloliative dermatitis, erythema multiorme, toxic epider. mat necrolysis. Stevens Johnson syndrome, vesiculo bullous reactions, photoallergic stón reactions

Central Nervous System: depression, insomnia, nervoesness

Urogenilas: hematuria, proteinuria, interstitial nephritis, renal tailure, hyperkalemia, olomeruilitis. papillary necrosis. ephrotec syndrome (see PRECAUTIONS)

Bady as a Whole: pain (colic), tever, flu-like syndrome (see PRECAUTIONS)

Special Senses: swollen eyes, blurred vision, eye irnitations

Cardiovascular Respiratory: hypertension, worsening of conpestive heart fallure (see PRECAUTIONS), exacerbation of angina

Metabolic: hypoglycemia, Ayperglycemia, weight increase, weight oecrease

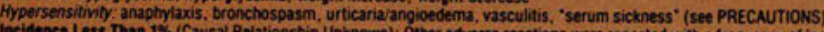

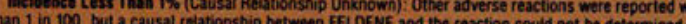
Gastrointestinar'pancreasitis

Dermatologic: onycholysis. loss of hair

Central Nervous System: akathisia. hallucinations, mood alterations, dream abnormalities, mental confusion, paresthesias

Uragenital System: dysuria

Body as a Whole: weaknes:

CardiovasculariRespiratory paipitations, dyspnes

Aypersensitivity: Dositive ANA
OVERDOSAGE: In the event treatment for overdosage is required, the long plasma halt-fite of piroxicam shouts be considered. The absence of experience with acute overdosage precludes characterization of sequelie and recommendations of peneral supportive therapy would apoly in addition to supoortive meensures, the use of activates of gastric evacuation an reduce the absorption and reabsorption of pirovicam. Experiments in dogs have domongtrated that the ose of may eflectivety treatments with activated charcoal could reduce the hall-kite of piroxicam Nimination from 27 hours (without charcenl) II hours and reduce the systemic bioavailability of piroxicam by as much as $37 \%$ when activated charcoal is given as inte as 6 hours after administration of piroxican

ADMINISTRANOW AND DOSAGE: Rheumatoid Arthritis, Osteoarthritis: It is recormmended that FELDENE therapy be in:tiated and maintained at a single daily dose of $20 \mathrm{mg}$. II desired. the daily dose may be dividec

Dosage recommendations and indications for use in children have not been established.

01982. Pizer ine

Reterencer: 1 . Siegmeth W: Serum concentrations of piroxicam in relation to its clinical effect in patients with chronic po vyarthritis (trans). Wien Med Wochenschr 130:31-35, 1980. 2. Tausch: Placebo-controlled study of piroxicam in the trea
ment of rheumatoid arthritis. Am J Med (report) 72:18-22, February 16. 1982. 